\title{
Medication Safety in Hospitals: Avoiding Medication Errors in the Medication Use Process
}

\author{
Samaranayake NR* $^{*}$ and Cheung BMY \\ Department of Medicine, University of Hong Kong, Hong Kong
}

\begin{abstract}
Medication errors have a large impact on patient safety and on healthcare costs. Although errors happen at every stage of the medication use process, the ones that occur in the latter part of the process are frequently undetected. Therefore, while all medication errors need to be eliminated, the ones that frequently reach the patient should be stopped first. Errors occur due to a combination of human and system-related failures. However, improving the system seems to be the prudent approach to avoiding medication errors, as human failures are inevitable. Efforts to improve systems include two broad areas. One is the automation of systems and the other is to improve the quality of prescription writing. Technologies have improved the safety of the medication use process to a large extent but this success depends on user acceptance. If technologies are difficult to use, users may work around standard procedures resulting in new and unanticipated errors. Bar-code assisted medication administration is one such useful technology which is commonly associated with implementation problems and workarounds. Therefore adequate preplanning, user attitude assessments and post-implementation assessments are three vital aspects of implementing new technology. Improving the quality of prescriptions is also a very useful strategy to improve medication safety, because a large percentage of hospitals still use hand-written prescriptions. The use of error-prone abbreviations has been shown to be very dangerous as pharmacists and nurses may misinterprit them, especially if the prescriptions are illegible. A popular approach to discourage error-prone abbreviations in prescriptions is through a 'Do Not Use' list; a list showing error-prone abbreviations that should be avoided by prescribers. However, its effectiveness and adherence by healthcare professionals has not been established. In conclusion, medication errors have a large impact on patient safety and interventions aimed at minimising them need careful planning and implementation.
\end{abstract}

Keywords: Medication errors; Technology-related errors; Errorprone abbreviations; Hospitals

\section{What is a 'Medication Error'?}

Medication errors are a threat to patient safety. These errors account for prolonged hospitalisations, extra medical interventions, morbidity and even death. Hence it is a preventable and unnecessary burden to both patients and hospitals. There are many different definitions of a medication error [1-9], but the most comprehensive and widely accepted definition was proposed by Ferner and Aronson [1]. They defined a medication error as a 'failure in the treatment process that lead to or has the potential to lead to harm to patients'. The 'treatment process' also known as the 'medication use process' is collectively, the prescribing, compounding, dispensing, drug administration, and monitoring processes, which are carried out after the decision for treatment has been made by the doctor. A 'failure' is the inability to attain a specified standard during the course of these processes. Most importantly, medication errors are preventable and can be avoided [10].

\section{Classification of Medication Errors}

Medication errors are commonly classified according to their cause, stage in the process and the severity of outcome. Each of these classifications provides vital information and therefore should be used together in the study of medication errors.

Psychologists classify medication errors according to the cause and the two main categories are; mistakes, and skill-based errors such as slips and lapses $[1,11,12]$. Mistakes happen when an error is made in the planned action. It may be due to lack of knowledge (knowledgebased errors), due to misapplication of a good rule, or application of a bad rule (rule-based error). For example, a knowledge-based error occurs when a doctor prescribes the wrong dose of a drug due to unfamiliarity. An example of a rule-based error is when a penicillin- related drug is prescribed to a patient with a known drug allergy to penicillin despite a system warning. On the other hand, skill-based errors are committed when executing correctly planned actions. A skill-based error could be a slip (action-based) where, for example, a pharmacy technician intends to dispense amoxicillin but picks the wrong bottle and dispenses ampicillin instead. It could also be a lapse (memory-based) where for example; a nurse intends, but forgets, to administer the evening dose of a drug to a patient (Figure 1). It is important to distinguish a medication error from a violation which is a deliberate disregard of formal instructions $[12,13]$

Medication errors are also classified according to the stage in the medication use process in which they occur. The most common categories in this classification are; prescribing, dispensing and drug administration errors $[1,11]$. Some further subdivide each category to more specific groups, such as wrong drug, wrong dose wrong frequency, wrong route and wrong patient [1].

Another important way of classification is by the severity or harm caused by the error. The most widely used severity scoring system for medication errors was introduced by the National Coordinating

*Corresponding author: Bernard MY Cheung, Department of Medicine, Queen Mary Hospital, 102, Pokfulam Road, Hong Kong, Tel: +852 2255 4347; Fax: +852 28186474; E-mail: mycheung@hku.hk

Received June 05, 2013; Accepted June 28, 2013; Published June 29, 2013

Citation: Samaranayake NR, Cheung BMY (2013) Medication Safety in Hospitals: Avoiding Medication Errors in the Medication Use Process. Adv Pharmacoepidem Drug Safety 2: 134. doi:10.4172/2167-1052.1000134

Copyright: (c) 2013 Samaranayake NR, et al. This is an open-access article distributed under the terms of the Creative Commons Attribution License, which permits unrestricted use, distribution, and reproduction in any medium, provided the original author and source are credited. 


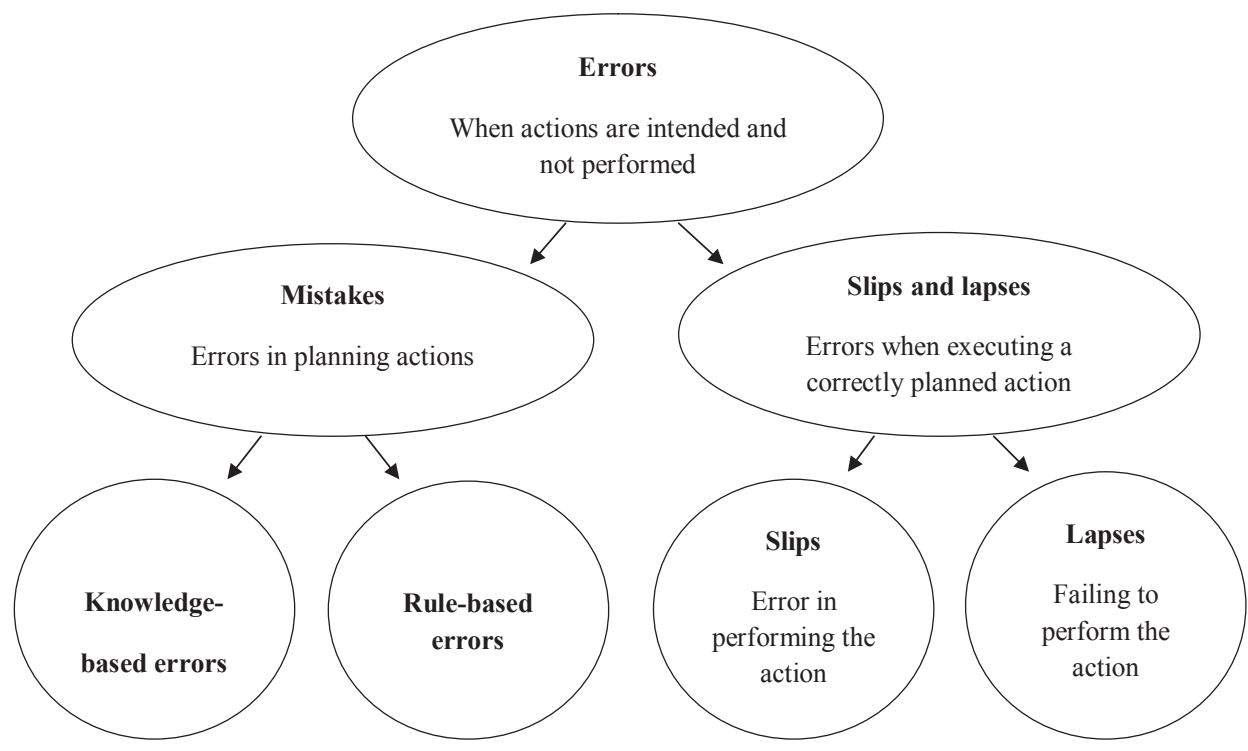

Figure 1: Mistakes, slips and lapses [10].

Council for Medication Error Reporting and Prevention (NCC MERP) of the United States, where the medication error is classified according to the degree of harm caused [14]. According to the NCC MERP, medication errors are categorised from A-I where for example, a category $\mathrm{C}$ medication error is an error that occurred and reached the patient but did not cause any harm, while a category $\mathrm{G}$ error is an error that occurred and needed interventions necessary to sustain life [15].

\section{Why Avoid Medication Errors?}

Medication errors have a large impact on patient safety and on healthcare cost [16-19]. There are not many studies that have directly assessed the economic impact of medication errors, but there are studies that explain the impact of preventable adverse drug events (ADEs) which is a serious type of medication error [20]. Adverse drug events (ADE) are defined as injuries resulting from medical interventions related to drugs [20]. Among these ADEs, the preventable ones are medication errors (Figure 2) [20-22]. At least 1.5 million preventable ADEs occur every year in the United States [20]. The average additional length of stay in a hospital due to preventable ADEs is 4.6 days in the tertiary setting and 3.15 days in community setting [18]. Preventable ADEs costs over $\$ 4685$ in tertiary hospitals [19] and $\$ 3511$ in community hospitals [18]. The estimated annual cost attributable to preventable ADEs in a 700 bed teaching hospital was 2.8 million dollars [19]. Bates et al studied 247 ADEs, of which 14 were life threatening, 30 were serious and 26 were significant preventable [16]. It is regrettable that preventable errors could cause such a significant threat to patient safety. Therefore preventing medication errors is a vital necessity.

\section{The Epidemiology of Medication Errors}

All medication errors need to be eliminated, but the ones that easily reach the patient should be stopped first. Errors that are detected and stopped before reaching the patient are important because they indicate what might happen in the future. The first step in avoiding medication errors is to understand the epidemiology, that is, the type of medication errors, where they originate, and whether errors are detected or missed before reaching the patient. Studies to date have shown that errors can happen at every stage of the medication use process $[16,23,24]$.
Prescribing errors are the most frequently occurring type, followed by drug administration errors and dispensing errors [16,23,24]. Among a handful of studies that have focused on this area, it has been shown that errors are more likely to be detected if they occur earlier in the medication use process $[16,24]$. This is because pharmacists and nurses play a role in the interception of errors that take place earlier in the system $[25,26]$. With the increased use of technology in prescribing, dispensing and drug administration, unanticipated errors can be introduced [27-30]. There is a need to study the pattern of interception of medication errors in contemporary clinical practice.

\section{Human and Systems Approaches to Avoiding Medication Errors}

The 'Swiss Cheese Model' (Figure 3) introduced by James Reason is an organisational model that is used in risk analysis and risk management of human systems [31]. The defensive layers of a system (or the steps in the medication use process) are compared to slices of Swiss cheese and the holes represent weaknesses in the defensive layers. According to this model, an error cannot pass through if holes in different layers do not align, but may do so if the holes in all the defensive layers line up to form a trajectory. Weaknesses in the system (represented by holes in the cheese) may arise due to two reasons, active failures and latent failures [12,31]. These two types of failures are distinguished by the length of time taken for a bad outcome to occur and the place in the organisational hierarchy where the errors originate. In a healthcare system, active failures are unsafe acts committed by people who are in direct contact with patients ('sharp end'), and these failures have immediate outcomes. They could be mistakes, slips or lapses made by prescribers, pharmacist and nurses when treating patients. On the other hand, latent failures are issues related to the system, such as failures in strategic decision making that take place higher up in the organisational hierarchy. Latent failures do not have immediate bad outcomes, and may lie dormant for a long time until they combine with an active failure to allow an error to happen. Therefore, according to Reason's theory a medication error is a result of not one, but a combination of both active and latent failures $[12,31]$. The human approach to avoiding medication errors is to stop active failures [31]. In this approach, medication errors are considered 


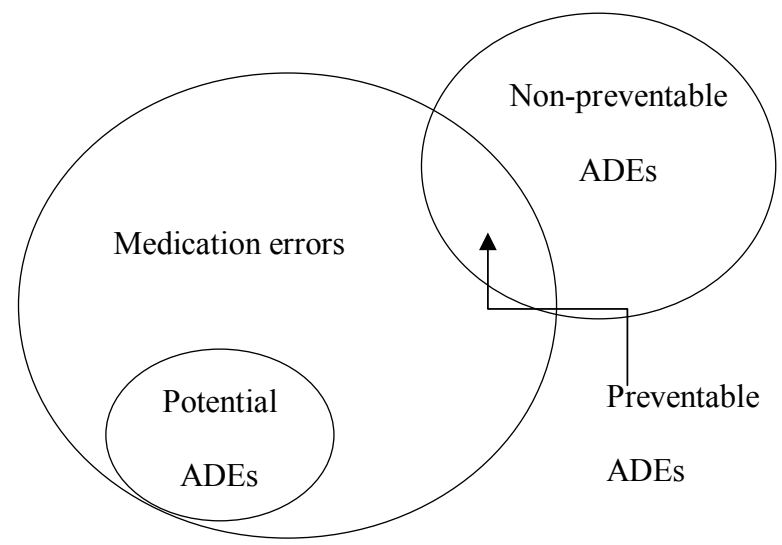

Figure 2: Adverse drug events (ADEs) and medication errors [20].

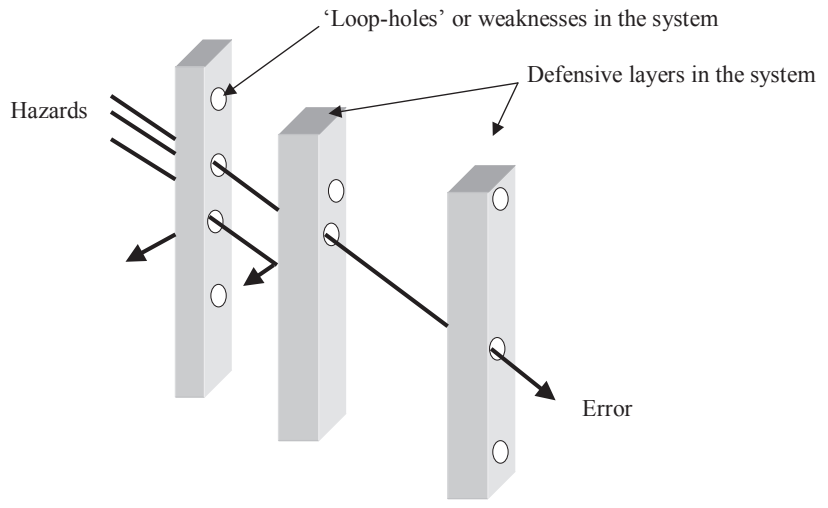

Figure 3: The Swiss Cheese Model [32].

a result of human negligence, carelessness and forgetfulness, and the culprits are often punished. This approach has now been shown to be ineffective because human errors are inevitable. The human approach may even discourage healthcare professionals to report errors that happened or nearly happened to avoid 'blame and shame'. A better way to tackle medication errors is stop latent failures and to improve the system in a way that errors cannot occur [31]. Unlike active failures, avoiding latent failures is more proactive as they can be detected before an error actually happens. Therefore experts now believe that a systems approach should be undertaken when attempting to avoid medication errors.

Hospitals spend a lot of effort to avoid medication errors by improving the system. The efficacy of these interventions has been extensively investigated in the last two decades. Among these interventions, there appear to be two broad approaches. One is to use technology or automation of the system to minimise medication errors. The other is to improve the quality of prescription writing.

\section{Technological Interventions to Avoid Medication Errors}

Computerised prescribing, bar-code technology to assist dispensing and drug administration, smart pumps for administering parenteral drugs and automated dispensers are some of the technologies widely used. Many studies have been conducted to evaluate the success [32-36] and failures of these technological interventions [27-30,32,37].

Computerised Prescription Order Entry (CPOE) has been employed extensively to reduce prescribing errors. It has been shown to reduce medication errors in in-patient $[33,38]$ and out-patient departments $[39,40]$ in hospitals. Electronic prescription reduces errors by standardising the medication order, reducing illegibility and reducing verbal orders [39-41]. The rate of adverse drug event reporting also improves after incorporating CPOE $[42,43]$. Song et al reported that medication incidents related to computerised prescriptions were much lower than incidents related to hand-written prescriptions [23].

Computerised Decision Support Systems (CDSS) integrated with CPOE have helped to reduce prescribing errors further [34,44-46]. CDSSs help prescribers in therapeutic decisions, dose, frequency, duration of drug therapy, allergy and side effects, and interactions with food and drugs [47-49]. A computer-based drug management program reduced a large proportion of ADEs caused by anti-infective agents [50]. Toxic doses of theophylline, warfarin and heparin have also been successfully reduced in patients using CDSS [51]. A dosing support system for common medicines, the 'quicklist', led to a reduction of 16.4 errors per 100 orders [52].

The Prescribing Information and Communications Systems (PICS) is an evolving system developed in Birmingham, England [53]. It combines electronic prescribing facilities together with patient history and reports, and contains algorithms to prompt the prescriber.

Many medication errors result from inadequate knowledge in prescribers and pharmacists and the use of Personal Digital Assistants (PDAs) or Palm Pilots has assisted in combating this problem. They work by linking the CPOE system with a medication information database where prescribers and pharmacists can seek information needed for prescribing, dispensing and counseling. PDAs have been shown to reduce prescribing and transcribing errors [54,55].

The introduction of Mobile Clinical Assistants (MCAs) integrated with Prescribing Information and Communication Systems (PICSs) has enabled prescribers to perform e-prescribing at the patient's bedside. It has been reported that MCAs helped to avoid 400 to 450 errors per week, save approximately $10 \%$ of the drug budget and reduce duplication of drug charts [56].

Automated dispensing machines can minimise dispensing errors [57] as well as drug administration errors such as omission errors and wrong time errors [58]. Drugs are stored according to the drug type or according to patient profile and the pharmacist or nurse can access the correct type, strength and quantity of drugs through the system.

Although the intravenous route of administration is a very effective and fast route, it can also cause disastrous consequences if a wrong drug or dose is administered. Use of "Smart" devices in intravenous administration, have shown to be effective in dose calculations, especially in reducing tenfold dosing errors $[59,60]$. Electronic dose calculations and dose checks would minimise harmful administration errors, especially for critical drugs such as narcotic drugs and chemotherapeutic agents $[59,61]$.

Bar-codes have been used in the medication use process to assist dispensing and drug administration errors, and to improve patient identification. Bar-code Assisted Drug Dispensing (BCDD) systems can improve the accuracy and timing of in-patient dispensing [62] and reduce wrong drug, wrong dose and wrong timing errors in the pharmacy [63]. Use of Bar-code Assisted Medication Administration (BCMA) systems can significantly reduce drug administration errors $[35,59,64]$. Non-timing drug administration errors were reduced from $11.5 \%$ to $6.8 \%$, the rate of potential ADEs from $3.1 \%$ to $1.6 \%$ and totally 
eliminated transcribing errors [35]. The VA Bar-Code Administration Project has prevented 378,000 drug administration errors since it was established in 1999 [65].

\section{Challenges in Implementing Technology in the Medication Use Process}

Although technological innovations help to improve medication

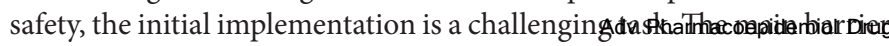

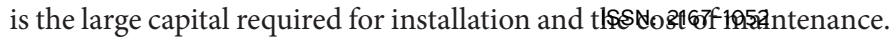
However, this initial investment may be offset by the reduction in the costs of medication errors and improved procedures [51]. Use of CPOE has shown cost savings of $\$ 5$ to $\$ 10$ million per year [66]. Bates estimated a cost saving of $\$ 2.8$ million by reducing preventable ADEs through a CPOE system [19]. A computer-assisted antibiotic dosing program has been shown to save $\$ 100,000$ per year due to reduced antibiotic dosing as well as reduced ADEs. However all these cost saving may be achieved only if the system is implemented successfully. A lot depends on user attitudes and acceptance of the technology. Usually, change is resisted by staff, especially if it increases the work load or requires unfamiliar skills [67]. Simple, easy to use systems are often accepted by user $[68,69]$ but they find ways around difficult and time consuming ones [29,64,70]. The danger is that these workarounds may give rise to unanticipated errors, and the envisioned benefits of the new system may not be achieved [27,71]. An unsuccessfully implemented technology would only result in de-motivated staff and decreased patient safety. The BCMA system is one such technology that has helped in minimising drug administration errors [35,72-74] but is associated with many implementation issues [29,71,75-77]. Koppel et al studied the use of BCMA in 2008 and found 15 types of workarounds by nurses due to 31 possible causes that they broadly categorised as technology-related, task-related, organisational, patient-related and environment-related factors [29]. Nurses overrode BCMA alerts on $10.3 \%$ of medications. Patterson et al reported that BCMA could give rise to new errors [70]. Therefore adequate pre-planning, user attitude assessments and postimplementation assessments are three vital aspects of implementing new technology.

\section{Improving the Quality of Hand-Written Prescriptions to Avoid Medication Errors}

Many errors can happen when there is missing or wrong information in the prescription, or when the prescription is illegible or incomprehensible. Even in the United States, a large number of hospitals still use hand-written prescriptions [78]. Strategies to improve the quality of prescriptions include using a standard prescription format with prompts for essential information [79] and 'one write' noncarbon prescription forms that generate an instant copy [80]. These have helped to improve the content of the prescription and reduce illegibility to an extent.

One area that has not been given due consideration is the use of inappropriate abbreviations and notations in prescriptions. Prescribers use abbreviations for convenience and to save time [81-83]. Sheppard et al revealed that 25 handover sheets and 108 medical notes contained over 221 types (2286 abbreviations) and 479 types (3368 abbreviations) of medical abbreviations respectively [84]. Another multicentre study carried out to evaluate the quality of prescription writing showed that abbreviations were used in more than $80 \%$ of prescriptions against $30 \%$ at one hospital that used electronic prescribing [85]. The real danger of using medical abbreviations is when prescriptions or medical records are written in illegible hand-writing. The abbreviations that look alike may be misinterpreted by pharmacists during dispensing and nurses during drug administration. A study conducted to assess the ability of multidisciplinary healthcare team members in a hospital to correctly interpret abbreviations used in medical records in an orthopedic ward demonstrated that only $57.2 \%$ of the abbreviations were recognised by orthopedic surgeons themselves [86]. Another study showed that 6 out of 13 ENT (Ear Nose Throat) related abbreviations were not clear to $90 \%$ of the junior doctors from different specialties [87].

Misinterpretation of abbreviaitions may lead to a great deal of harm to patients. For example, 'QID' (four times a day) is often confused with 'QD' (once daily). A patient died because furosemide $40 \mathrm{mg}$ QD was misinterpreted as furosemide $40 \mathrm{mg}$ Q.I.D [88]. Writing ' $\mathrm{u}$ ' instead of 'units' also leads to frequent misinterpretations, as it runs the risk of being misinterpreted as an additional ' 0 ' that increases the intended dose 10 times. This could be dangerous when prescribing drugs such as insulin and heparin [65]. Using a trailing zero after a decimal point or failing to write a zero before a decimal point is also unsafe as the decimal point may be missed by the interpreter. A reported 'near miss' was on Alprozolam $1.0 \mathrm{mg}$ which was misinterpreted as $10 \mathrm{mg}$ [65]. The tragic death of a nine month year old baby in 2001 and an infant death in 2000 , both due to the misinterpretation of 'morphine $.5 \mathrm{mg}$ ' as 'morphine $5 \mathrm{mg}$ ' illustrate the danger of this practice [89].

Using standard approved abbreviations in prescriptions is harmless but abbreviations that are identified as error-prone should be avoided. Among the many strategies $[79,80]$, a common approach used by many hospitals, and recommended by many safety organisations, is to introduce a 'Do Not Use' list [90-92]. This is a list of error-prone abbreviations that should be avoided by prescribers and the list may differ according to the prescribing patterns of different hospitals. Although many hospitals have adopted this intervention, its effectiveness and adherence by healthcare professionals have not been studied in detail.

Healthcare professionals who are involved in writing and reading prescriptions play a large role in eliminating error-prone abbreviations and the success of related interventions may depend on their attitudes. Prescribers use abbreviations in prescriptions to save time but they are disliked by pharmacists and nurses who have to interpret them. Teaching medical undergraduates prescribing may help them develop safe attitude and practices towards prescribing [93].

\section{Conclusions}

Medication errors affect patient safety and needs to be eliminated. As human errors are inevitable, the system needs to be improved in a way that errors would not happen. Technological interventions and improving the quality of hand-written prescription are two widely used approaches to improve the system. Technologies have helped to reduce medication errors but the success is greatly dependant on user acceptance. Therefore, careful planning, user attitude assessments and post-implementation assessments are needed when adopting technological innovations. The use of error-prone abbreviations in prescriptions has led to patient harm. Some hospitals that use handwritten prescriptions have introduced 'Do Not Use' lists that specify error-prone abbreviations that prescribers should avoid when writing prescriptions, but its effectiveness has not been clearly studied. Therefore hospitals that use hand-written prescriptions need more carefully planned and monitored interventions to eliminate the use of error-prone abbreviations.

\section{References}

1. Ferner RE, Aronson JK (2006) Clarification of terminology in medication errors definitions and classification. Drug Saf 29: 1011-1022. 
Citation: Samaranayake NR, Cheung BMY (2013) Medication Safety in Hospitals: Avoiding Medication Errors in the Medication Use Process. Adv Pharmacoepidem Drug Safety 2: 134. doi:10.4172/2167-1052.1000134

2. Barker KN, Mikeal RL, Pearson RE, Illig NA Morse ML (1982) Medication errors in nursing homes and small hospitals. Am J Hosp Pharm 39: 987-991.

3. Barker KN, Flynn EA, Pepper GA, Bates DW, Mikeal RL (2002) Medication errors observed in 36 health care facilities. Arch Intern Med 162: 1897-1903.

4. Taxis K, Barber N (2003) Causes of intravenous medication errors: an ethnographic study. Qual Saf Health Care 12: 343-347.

5. (1993) ASHP guidelines on preventing medication errors in hospitals. Am $J$ Hosp Pharm 50: 305-314

6. (1998) Suggested definitions and relationships among medication misadventures, medication errors, adverse drug events, and adverse drug reactions. Am J Health Syst Pharm 55: 165-166.

7. Kaushal R, Bates DW, Landrigan C, McKenna KJ, Clapp MD, et al. (2001) Medication errors and adverse drug events in pediatric inpatients. JAMA 285 2114-2120.

8. The National Coordinating Council for Medication Error Reporting and Prevention. (1997) National Council focuses on coordiating error reduction efforts. Quality Review.

9. Dean B, Barber N, Schachter M (2000) What is a prescribing error? Qual Health Care 9: 232-237.

10. Ferner RE (2012) Medication errors. Br J Clin Pharmacol 73: 912-916.

11. Betz RP, Levy HB (1985) An interdisciplinary method of classifying and monitoring medication errors. Am J Hosp Pharm 42: 1724-1732.

12. Reason J (1995) Understanding adverse events: human factors. Qual Health Care 4: 80-89.

13. McDowell SE, Ferner HS, Ferner RE (2009) The pathophysiology of medication errors: how and where they arise. Br J Clin Pharmacol 67: 605-613.

14. Hartwig SC, Denger SD, Schneider PJ (1991) Severity-indexed, incident reportbased medication error-reporting program. Am J Hosp Pharm 48: 2611-2616.

15. National Coordinating Council for Medication Error Reporting and Prevention (1998) NCC MERP Taxonomy of Medication Errors

16. Bates DW, Cullen DJ, Laird N, Petersen LA, Small SD, et al. (1995) Incidence of adverse drug events and potential adverse drug events. Implications for prevention. ADE Prevention Study Group. JAMA 274: 29-34.

17. Kunac DL, Kennedy J, Austin N, Reith D (2009) Incidence, preventability, and impact of Adverse Drug Events (ADEs) and potential ADEs in hospitalized children in New Zealand: a prospective observational cohort study. Paediatr Drugs 11: 153-160.

18. Hug BL, Keohane C, Seger DL, Yoon C, Bates DW (2012) The costs of adverse drug events in community hospitals. Jt Comm J Qual Patient Saf 38: 120-126.

19. Bates DW, Spell N, Cullen DJ, Burdick E, Laird N, et al. (1997) The costs of adverse drug events in hospitalized patients. Adverse Drug Events Prevention Study Group. JAMA 277: 307-311.

20. Board on Health Care Services. (2007) Preventing medication errors: quality chasm Series. Aspden P, Wolcott J, Bootman JL, Cronenwett LR, editors: The National Academies Press.

21. Bates DW, Boyle DL, Vander Vliet MB, Schneider J, Leape L (1995) Relationship between medication errors and adverse drug events. J Gen Intern Med 10 199-205

22. Morimoto T, Gandhi TK, Seger AC, Hsieh TC, Bates DW (2004) Adverse drug events and medication errors: detection and classification methods. Qual Sa Health Care 13: 306-314.

23. Song L, Chui WC, Lau CP, Cheung BM (2008) A 3-year study of medication incidents in an acute general hospital. J Clin Pharm Ther 33: 109-114

24. Leape LL, Bates DW, Cullen DJ, Cooper J, Demonaco HJ, et al. (1995) Systems analysis of adverse drug events. ADE Prevention Study Group. JAMA 274: 35-43.

25. Wang JK, Herzog NS, Kaushal R, Park C, Mochizuki C, et al. (2007) Prevention of pediatric medication errors by hospital pharmacists and the potential benefit of computerized physician order entry. Pediatrics 119: e77-85

26. Ito $\mathrm{H}$, Yamazumi S (2003) Common types of medication errors on long-term psychiatric care units. Int J Qual Health Care 15: 207-212.
27. Redwood S, Rajakumar A, Hodson J, Coleman JJ (2011) Does the implementation of an electronic prescribing system create unintended medication errors? A study of the sociotechnical context through the analysis of reported medication incidents. BMC Med Inform Decis Mak 11: 29.

28. Walsh KE, Adams WG, Bauchner H, Vinci RJ, Chessare JB, et al. (2006) Medication errors related to computerized order entry for children. Pediatrics 118: 1872-1879.

29. Koppel R, Wetterneck T, Telles JL, Karsh BT (2008) Workarounds to barcode medication administration systems: their occurrences, causes, and threats to patient safety. J Am Med Inform Assoc 15: 408-423.

30. Koppel R, Metlay JP, Cohen A, Abaluck B, Localio AR, et al. (2005) Role of computerized physician order entry systems in facilitating medication errors. JAMA 293: 1197-1203.

31. Reason J (2000) Human error: models and management. BMJ 320: 768-770.

32. Fanikos J, Fiumara K, Baroletti S, Luppi C, Saniuk C, et al. (2007) Impact of smart infusion technology on administration of anticoagulants (unfractionated Heparin, Argatroban, Lepirudin, and Bivalirudin). Am J Cardiol 99: 1002-1005.

33. Walsh KE, Landrigan CP, Adams WG, Vinci RJ, Chessare JB, et al. (2008) Effect of computer order entry on prevention of serious medication errors in hospitalized children. Pediatrics 121: e421-427.

34. Kaushal R, Kern LM, BarrÃ $\tilde{n}^{n}$ Y, Quaresimo J, Abramson EL (2010) Electronic prescribing improves medication safety in community-based office practices. J Gen Intern Med 25: 530-536.

35. Poon EG, Keohane CA, Yoon CS, Ditmore M, Bane A, et al. (2010) Effect of bar-code technology on the safety of medication administration. N Engl J Med 362: 1698-1707.

36. Poon EG, Cina JL, Churchill WW, Mitton P, McCrea ML, et al. (2005) Effect of bar-code technology on the incidence of medication dispensing errors and potential adverse drug events in a hospital pharmacy. AMIA Annu Symp Proc

37. Harrison MI, Koppel R, Bar-Lev S (2007) Unintended consequences of information technologies in health care--an interactive sociotechnical analysis. J Am Med Inform Assoc 14: 542-549.

38. Bates DW, Teich JM, Lee J, Seger D, Kuperman GJ, et al. (1999) The impact of computerized physician order entry on medication error prevention. J Am Med Inform Assoc 6: 313-321.

39. Kaplan JM, Ancheta R, Jacobs BR; Clinical Informatics Outcomes Research Group (2006) Inpatient verbal orders and the impact of computerized provider order entry. J Pediatr 149: 461-467.

40. Jani YH, Ghaleb MA, Marks SD, Cope J, Barber N, et al. (2008) Electronic prescribing reduced prescribing errors in a pediatric renal outpatient clinic. $J$ Pediatr 152: 214-218.

41. Devine EB, Hansen RN, Wilson-Norton JL, Lawless NM, Fisk AW, et al. (2010) The impact of computerized provider order entry on medication errors in multispecialty group practice. J Am Med Inform Assoc 17: 78-84.

42. Yu F, Salas M, Kim Yl, Menachemi N (2009) The relationship between computerized physician order entry and pediatric adverse drug events: a nested matched case-control study. Pharmacoepidemiol Drug Saf 18: 751-755.

43. Weant KA, Cook AM, Armitstead JA (2007) Medication-error reporting and pharmacy resident experience during implementation of computerized prescriber order entry. Am J Health Syst Pharm 64: 526-530.

44. Kazemi A, Ellenius J, Pourasghar F, Tofighi S, Salehi A, et al. (2011) The effect of Computerized Physician Order Entry and decision support system on medication errors in the neonatal ward: experiences from an Iranian teaching hospital. J Med Syst 35: 25-37.

45. Kadmon G, Bron-Harlev E, Nahum E, Schiller O, Haski G, et al. (2009) Computerized order entry with limited decision support to prevent prescription errors in a PICU. Pediatrics 124: 935-940.

46. van Doormaal JE, van den Bemt PM, Zaal RJ, Egberts AC, Lenderink BW, et al. (2009) The influence that electronic prescribing has on medication errors and preventable adverse drug events: an interrupted time-series study. J Am Med Inform Assoc 16: 816-825.

47. Kaushal R, Shojania KG, Bates DW (2003) Effects of computerized physician order entry and clinical decision support systems on medication safety: a systematic review. Arch Intern Med 163: 1409-1416. 
Citation: Samaranayake NR, Cheung BMY (2013) Medication Safety in Hospitals: Avoiding Medication Errors in the Medication Use Process. Adv Pharmacoepidem Drug Safety 2: 134. doi:10.4172/2167-1052.1000134

48. Matsumura $Y$, Yamaguchi T, Hasegawa H, Yoshihara $\mathrm{K}$, Zhang Q, et al (2009) Alert system for inappropriate prescriptions relating to patients' clinical condition. Methods Inf Med 48: 566-573.

49. Terrell KM, Perkins AJ, Dexter PR, Hui SL, Callahan CM, et al. (2009) Computerized decision support to reduce potentially inappropriate prescribing to older emergency department patients: a randomized, controlled trial. J Am Ger Soc. 57:1388-1394.

50. Evans RS, Pestotnik SL, Classen DC, Clemmer TP, Weaver LK, et al. (1998) A computer-assisted management program for antibiotics and other antiinfective agents. N Engl J Med 338: 232-238.

51. Hurley SF, Dziukas LJ, McNeil JJ, Brignell MJ (1986) A randomized controlled clinical trial of pharmacokinetic theophylline dosing. Am Rev Respir Dis 134 1219-1224.

52. Sard BE, Walsh KE, Doros G, Hannon M, Moschetti W, et al. (2008) Retrospective evaluation of a computerized physician order entry adaptation to prevent prescribing errors in a pediatric emergency department. Pediatrics 122: 782-787.

53. Davidson L (2010) Birmingham PICS CSE as partner. [cited 201025 June 2010].

54. Grasso BC, Genest R (2001) Clinical computing: Use of a personal digital assistant in reducing medication error rates. Psychiatr Serv 52: 883-884, 886.

55. Grasso BC, Genest R, Yung K, Arnold C (2002) Reducing errors in discharge medication lists by using personal digital assistants. Psychiatr Serv 53: 13251326.

56. Harris C (2010) Motion's C5 Mobile clinical assistant significantly enhances patient care at university hospitals birmingham nhs foundation trust. [cited 2010 25 June 2010]

57. Chapuis C, Roustit M, Bal G, Schwebel C, Pansu P, et al. (2010) Automated drug dispensing system reduces medication errors in an intensive care setting. Crit Care Med 38: 2275-2281.

58. Barker KN, Pearson RE, Hepler CD, Smith WE, Pappas CA (1984) Effect of an automated bedside dispensing machine on medication errors. Am J Hosp Pharm 41: 1352-1358.

59. Kaushal R, Bates DW (2002) Information technology and medication safety: what is the benefit? Qual Saf Health Care 11: 261-265.

60. Koren G, Barzilay Z, Greenwald M (1986) Tenfold errors in administration of drug doses: a neglected iatrogenic disease in pediatrics. Pediatrics 77: 848849 .

61. Taylor JA, Loan LA, Kamara J, Blackburn S, Whitney D (2008) Medication administration variances before and after implementation of computerized physician order entry in a neonatal intensive care unit. Pediatrics 121: 123-128.

62. Meyer GE, Brandell R, Smith JE, Milewski FJ Jr, Brucker P Jr, et al. (1991) Use of bar codes in inpatient drug distribution. Am J Hosp Pharm 48: 953-966.

63. Bates DW, Teich JM, Lee J, Seger D, Kuperman GJ, et al. (1999) The impact of computerized physician order entry on medication error prevention. J Am Med Inform Assoc 6: 313-321.

64. Morriss FH Jr, Abramowitz PW, Carmen L, Wallis AB (2009) "Nurses Don't Hate Change" -- survey of nurses in a neonatal intensive care unit regarding the implementation, use and effectiveness of a bar code medication administration system. Healthc Q 12 Spec No Patient: 135-140.

65. Benjamin DM (2003) Reducing medication errors and increasing patient safety: case studies in clinical pharmacology. J Clin Pharmacol 43: 768-783.

66. Teich J, Glaser J, Beckley R, et al. (1996) Toward cost-effective, quality care: the Brigham Integrated Computing System. Proceedings From the Second Annual Nicholas E Davies CPR Recognition Symposium; 1996; Washington, DC: Computer-based Patient Record Institute.

67. Karsh BT, Holden RJ, Alper SJ, Or CK (2006) A human factors engineering paradigm for patient safety: designing to support the performance of the healthcare professional. Qual Saf Health Care 15 Suppl 1: i59-65.

68. Zhang H, Cocosila M, Archer N (2010) Factors of adoption of mobile information technology by homecare nurses: a technology acceptance model 2 approach. Comput Inform Nurs 28: 49-56.

69. de Veer AJ, Francke AL (2010) Attitudes of nursing staff towards electronic patient records: a questionnaire survey. Int J Nurs Stud 47: 846-854.
70. Patterson ES, Rogers ML, Chapman RJ, Render ML (2006) Compliance with intended use of Bar Code Medication Administration in acute and long-term care: an observational study. Hum Factors 48: 15-22.

71. DiConsiglio J (2008) Creative 'work-arounds' defeat bar-coding safeguard for meds. Study finds technology often doesn't meet the needs of nurses. Mater Manag Health Care 17: 26-29.

72. Paoletti RD, Suess TM, Lesko MG, Feroli AA, Kennel JA, et al. (2007) Using bar-code technology and medication observation methodology for safe medication administration. Am J Health Syst Pharm 64: 536-543.

73. Franklin BD, O'Grady K, Donyai P, Jacklin A, Barber N (2007) The impact of a closed-loop electronic prescribing and administration system on prescribing errors, administration errors and staff time: a before-and-after study. Qual Saf Health Care 16: 279-284.

74. Mahoney CD, Berard-Collins CM, Coleman R, Amaral JF, Cotter CM (2007) Effects of an integrated clinical information system on medication safety in a multi-hospital setting. Am J Health Syst Pharm 64: 1969-1977.

75. Mills PD, Neily J, Mims E, Burkhardt ME, Bagian J (2006) Improving the barcoded medication administration system at the Department of Veterans Affairs. Am J Health Syst Pharm 63: 1442-1447.

76. Mims E, Tucker C, Carlson R, Schneider R, Bagby J (2009) Quality-monitoring program for bar-code-assisted medication administration. Am J Health Sys Pharm 66: 1125-1131.

77. FitzHenry F, Doran J, Lobo B, Sullivan TM, Potts A, et al. (2011) Medicationerror alerts for warfarin orders detected by a bar-code-assisted medication administration system. Am J Health Syst Pharm 68: 434-441.

78. Whyte M (2005) Computerised versus handwritten records. Paediatr Nurs 17 $15-18$.

79. Kennedy AG, Littenberg B (2004) A modified outpatient prescription form to reduce prescription errors. Jt Comm J Qual Saf 30: 480-487.

80. Miller LG, Matson CC, Rogers JC (1992) Improving prescription documentation in the ambulatory setting. Fam Pract Res J 12: 421-429.

81. Kuhn IF (2007) Abbreviations and acronyms in healthcare: when shorter isn't sweeter. Pediatr Nurs 33: 392-398.

82. Kushlan JA (1995) Use and abuse of abbreviations in technical communication J Child Neurol 10: 1-3.

83. Dunn EB, Wolfe JJ (2001) Let go of Latin! Vet Hum Toxicol 43: 235-236

84. Sheppard JE, Weidner LC, Zakai S, Fountain-Polley S, Williams J (2008) Ambiguous abbreviations: an audit of abbreviations in paediatric note keeping Arch Dis Child 93: 204-206.

85. Miasso Al, Oliveira RC, Silva AE, Lyra Junior DP, Gimenes FR, et al. (2009) Prescription errors in Brazilian hospitals: a multi-centre exploratory survey. Cad Saude Publica 25: 313-320.

86. Parvaiz MA, Subramanian A, Kendall NS (2008) The use of abbreviations in medical records in a multidisciplinary world--an imminent disaster. Commun Med 5: 25-33.

87. Das-Purkayastha P, McLeod K, Canter R (2004) Specialist medical abbreviations as a foreign language. J R Soc Med 97: 456.

88. von Eschenbach AC (2007) Eliminating error-prone notations in medical communications. Expert Opin Drug Saf 6: 233-234.

89. Institute of Safe Medication Practices (2001) Please dont sleep through this wake up call.Medication Safety Alert! [cited 2011 March].

90. Hong Kong Health Authority, Medication Safety Committee (2010) The 'Do Not Use list'. [cited 2010 August]

91. The Joint Commission. (2004) Official 'Do Not Use' list of abbreviations. [cited 201015 July]

92. Australian Commission on Safety and Quality in Healthcare (2006) Nationa terminology, abbreviations and symbols to be used in the prescribing and administering of medicines in Australian hospitals. [cited $2011 \mathrm{March}$.

93. Sandilands EA, Reid K, Shaw L, Bateman DN, Webb DJ, et al. (2011) Impact of a focussed teaching programme on practical prescribing skills among final year medical students. Br J Clin Pharmacol 71: 29-33. 